\title{
A Review on Chicane Design based on Calming Theory
}

\author{
Chunli Zhang ${ }^{1}$, Song Qin ${ }^{2}$, Hongjiang $\mathrm{Yu}^{1,3, *}$, Binshuang Zheng ${ }^{4}$ and Zhen $\mathrm{Li}^{5}$ \\ ${ }^{I}$ Chongqing Jianzhu College, Chongqing 400072, China \\ ${ }^{2}$ General Research Institute of Architecture \& Planning Design Co. Ltd, Chongqing University, Chongqing 400045, China \\ ${ }^{3}$ Intelligent Road Detection in Mountainous City Engineering Research Center of Chongqing Education Commission, Chongqing \\ 400072, China \\ ${ }^{4}$ Southeast University, Nanjing 211189, China \\ ${ }^{5}$ Faculty of Engineering, Computer and Mathematical Sciences, The University of Adelaide, Adelaide, South Australia 5005, Australia
}

Received 12 March 2020; Accepted 27 June 2020

\begin{abstract}
Chicane has been widely recognized and applied as a traffic calming measure to decrease vehicle speed, reduce traffic accidents, and improve arterial traffic. The design of chicane is influenced by various factors. To analyze the influencing factors of chicane design systematically, investigate chicane design on the basis of traffic calming theory, and summarize the development trend of chicane, this study reviewed the explore progress in the structure setting form of chicane, geometric design parameters, and influencing factors of traffic safety. Moreover, the uncertainties in the natural environment and operation process were analyzed, and the future development direction of chicane in urban road calming technology was discussed. Results demonstrate that chicane is an extremely effective traffic facility to ensure traffic safety. The geometric design of chicane mainly focuses on free view width $a$ and stagger length $l$. However, the existing design of chicane is not uniform, and driving behavior is not standard.
\end{abstract}

Keywords: calming theory, chicane, urban residential area, geometric design, traffic accident

\section{Introduction}

Social development has continuously improved the appearance of cities and quality of life. The principles of "safety, efficiency, and comfort" of highway and urban road construction have gradually changed to "safety, efficiency, comfort, and beauty" in China [1]. With the increase of aesthetic value, people have raised their demand for beauty. Reflecting the factors influencing aesthetic feeling in the design of urban roads, which conforms to the comfortable and beautiful features of calming facilities, has become an inevitable trend [2]. Road calming facilities generally refer to road deceleration facilities, such as chicanes, speed control humps, and safety islands. Chicanes, as traffic calming measures to decrease vehicle speed, reduce traffic accidents, and improve road traffic, have been widely recognized and applied. They have the following functions. (1) Chicanes in residential areas can change the perception of drivers toward the road structure. Thus, drivers move at a suitable speed, thereby improving driving comfort [3]. (2) Chicanes can moderately reduce noise and air pollution, beautify pavement landscape, and respond to road engineering strategies for green environmental protection [4] (3) Chicanes are suitable for one-way, two-way, and nonmixed roads with sufficient parking space. (4) Chicanes are generally designed with a road arch or a speed buffer zone. Therefore, chicane design is significant in landscape design, driving comfort, and traffic safety in residential areas.

However, when the lateral deflection of the lane is too large; the vehicle deviates from the ideal path; or in special

*E-mail address: cqigzy111@163.com

ISSN: 1791-2377 @ 2020 School of Science, IHU. All rights reserved.

doi:10.25103/jestr.134.18 weather (snowy, rainy, and haze), heavy traffic, and densely populated residential areas, vehicles are likely to roll over, slip, or encounter blind areas when passing chicanes [5]. Therefore, chicane design must be standardized to prevent vehicles from deviating from the carriageway [6]. The theory of chicane design should be further explored according to traffic calming principles and uncertainty factors; the corresponding geometric design and evaluation criteria should be formulated, which is an effective strategy to facilitate the development and standardized popularization of chicanes and to promote green transportation in China.

According to the study status of chicane design based on calming theory, this study aims to find the problems in chicane design, expound the current study hotspots of chicane, and determine the design and application direction. The results can provide a theoretical basis for the standardization of chicane design and a certain engineering application value.

The remainder of this study is organized as follows. Part Two makes an overview for study on traffic calming measures and current study situations of chicane. Part Three introduces the geometric design for chicane. Part Four examines the design criteria appropriate for chicane internationally. Part Five analyzes the influential factors affecting chicane design. The final part makes a summary for the study and derives related conclusions.

\section{State of the art}

\subsection{Traffic calming measures}

Calming theory originates from the recognition of uncertainty factors (safety, habitability, harmony, and walkability) in road traffic operation and the need for driving 
comfort in road engineering structure design. In the early 1960s, Woonerf in Holland proposed the concept of traffic calming, which was a new deceleration concept and technology for road traffic planning, design, and management [7-11]. Since "Traffic in Town" was published by Colin Buchanan in the United Kingdom in 1963, scholars from the European Union have studied traffic calming [1214]. The Institute of Transportation Engineering (ITE) elaborated the specific connotation of traffic calming in Tampa City, Florida and formally conceptualized traffic calming in the ITE Traffic Calming Definition.

Soon afterward, Scholars in Berkeley in California in the United States made the first systematic planning and design of traffic calming [15-17]. The physical speed and direction of urban roads was systematically regulated to change the road alignment and implement a road diversion plan, thereby improving the environment of pedestrians and motor vehicles and achieving the effects of traffic safety, harmony, and livability [18-20].

In 2017, the Federal Highway Administration (FHWA) and ITE defined traffic calming as a method to improve the safety, mobility, and comfort of non-motor vehicle drivers by reducing vehicle speed or traffic on a single street or street network. Traffic calming measures include horizontal measures, vertical measures, lane-narrowing measures, and roadside measures. These measures use mandatory physical or psychological perception to achieve the desired results.

With the constant promotion and application of traffic calming measures, the definition of traffic calming has become increasingly diversified. However, the basic idea is the same: traffic calming reduces the speed of vehicles, upgrades the living quality of residential and commercial areas, enhances the safety and comfort of outdoor activities, promotes the balance of various transportation modes, and improves the role of road landscape by taking physical measures [21-22].

Numerous traffic calming measures have been applied around the world, and the specific effects of these traffic calming measures have also been investigated [23-25]. In 1979, Ashton [26] comprehensively studied traffic accidents in Britain, finding that when the vehicle speed is below 30 mph, traffic accidents are minimal and cause little loss. In 1994, Finch et al. [27] explored the relationship between vehicle speed and traffic accident frequency and pointed out that overspeeding has a significant impact on the increase of accident rates. Many studies have demonstrated that proper traffic calming measures can significantly alleviate traffic congestion [28] and reduce traffic accident rates [29-31]. Similarly, scholars from the University of Leeds and Cottrell et al. [32-33] used a software simulation method to simulate the vehicle emission and accident rates of speed humps and drew a similar conclusion that speed humps can significantly decrease vehicle emission and accident rates. Traffic calming measures on the vertical elevation, such as speed humps, can effectively control vehicle speed [34].

However, previous studies have shown that vertical traffic calming measures have many drawbacks. For example, the changes in elevation may cause additional traffic noise resulting from acceleration, deceleration, and humps [35-39]. Some studies have compared traffic flow velocities under different traffic calming measures and analyzed the economic efficiency of traffic calming measures from the perspective of environmental carbon emission. Thus, traffic calming measures, which require vehicles to reduce speed rather than to stop (such as chicanes), can lead to less carbon emission and air pollution compared with stop-required traffic calming measures proposed by existing study [40-41].

The study of traffic calming theory is scarce in China. In 2006, Jin Jian [42] surveyed residents in seven residential areas and found that vehicle owners and non-motor vehicle owners believe that motor vehicles significantly influence the safety of residential areas; moreover, these owners hold positive attitudes toward traffic calming measures. In 2019, Chen Kangwen [43] analyzed the influence of different stabilizing measures on the deceleration effect, operation efficiency, and traffic safety; Chen also pointed out that traffic calming design reflects "people-orientedness." $\mathrm{Xu}$ Liangjie [44] proposed a systematic traffic calming improvement design for traffic safety in campus to ensure the smoothness of driving speed and walkability in campus.

\subsection{Chicanes}

With the rapid development of road traffic, the planning mode of urban residential areas can hardly adapt to the changing urban environment, and the traffic problems in residential areas have become increasingly prominent. On the basis of the concept of traffic calming, different chicanes in urban residential areas and densely populated commercial streets have been designed. All kinds of chicanes have been widely used to reduce vehicle speed. In particular, considering the friendly coexistence of vehicle exhaust, noise, living environment, and the civilized traffic of pedestrians and vehicles, the driving speed of vehicles, such as cars and fire engines, must be controlled in residential areas. Chicanes, as a traffic calming measure, have evident advantages in residential areas. Chicanes have been set earlier in developed cities.

According to pavement function and the characteristics of road space layout, a chicane is defined as a carriageway formed by alternately extending the curbs on both sides of roads or alternately setting parking berths oblique or parallel to the carriageway. A chicane is S-shaped, as shown in Figure 1, and it is designed to reduce vehicle speed in lateral deflection, which can significantly decrease the safety risks of non-motorized vehicles and pedestrians caused by motor vehicles.

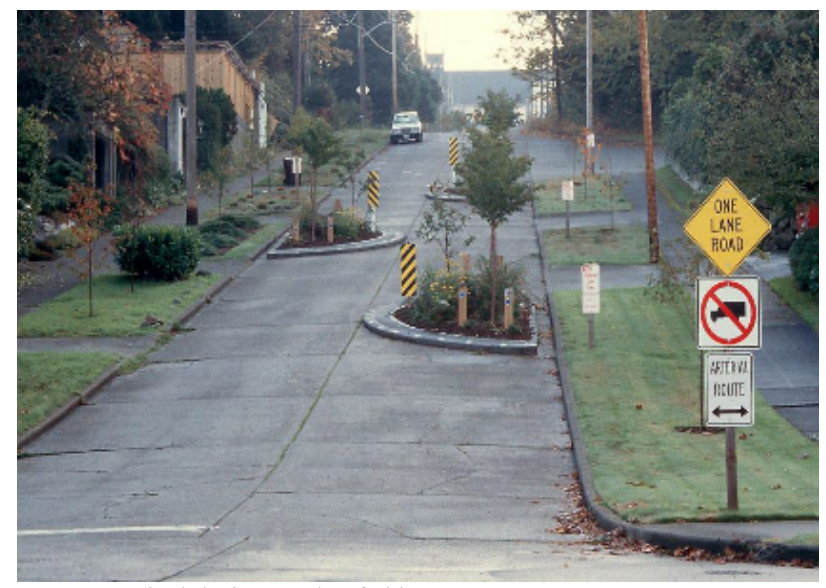

Fig. 1. Typical design mode of chicanes

In 1980, Japanese scholars carried out a speed test of large fire engines passing through a straight road and a chicane. The test results proved that the chicane has a great impact on vehicle speed, and the speed of the fire engine on the chicane decreased by $2 \%$ compared with that on the straight road. 
In 1983, the traffic management department of the Seattle municipal government assessed the deceleration effect of the overall closure and setting speed limit of chicanes to decrease the impact of highways on vehicle loads of community streets. By comparison, city staff suggested setting up unrestricted chicanes in community streets. In the next year, two chicanes with a distance of 420 feet were set in a street. Each chicane consists of three roadside bulbs with the distance of feet and extends to approximately 13 feet along the street.

In Denmark and the United Kingdom, the concept of a "20 km/h speed zone" in chicanes has been widely used in rural roads and some low-speed roads [45-48]. Meanwhile, some guidelines have been set for traffic calming design, including chicanes in Europe and North America [49].

In February 1994, to make recommendations for the local highway bureau, the transport research laboratory carried out an experimental study on chicane design and lateral deflection performance on a test track by using automobiles and oversized vehicles as the test objects. According to the test results, Sayer [50] established the relationship between the average speed of vehicles passing chicanes and the geometric parameters of chicanes (such as stagger length, free view width, lane width, and sight distance restriction). On the basis of the information provided by drivers, environment, transportation, and the local transportation management department, the setting of chicanes on highways was further studied. Moreover, different chicane design schemes were introduced from the aspects of design, location, deceleration effect, and accident reduction rate. By comparing the results of the TRL test, average speed, and path angle, the deceleration effect of different design schemes was analyzed.

In 1997, the traffic department of the United Kingdom indicated that using chicanes as a measure of traffic calming can significantly reduce the probability of serious traffic accidents [51]. In the same year, Kawakami [52] studied the traffic calming technology and set up two types of chicanes on the test road in Jinze, Japan to investigate the impact of traffic environment. Chicane can restrict the speed of vehicles to some extent. However, given the limited pedestrian space, the awareness of pedestrian traffic safety has not improved. Implementing traffic safety rules in residential areas are of great importance.

To limit the vehicle speed of a block in a residential area in Seattle, Washington in 1998, Marek [53] set up 13 chicanes (forming an $\mathrm{S}$ shape using three roadside lights to narrow the road to a one-way road), and 32 chicanes on the uphill road. Approximately $97 \%$ of the test vehicles ran at 25 mile/h $(40 \mathrm{~km} / \mathrm{h})$. The speed of $85 \%$ of the vehicles decreased by $10 \mathrm{mile} / \mathrm{h}(16 \mathrm{~km} / \mathrm{h})$ when passing the chicanes. When passing the speed humps, the speed of $85 \%$ of the vehicles decreased by approximately $12 \mathrm{mile} / \mathrm{h}(19 \mathrm{~km} / \mathrm{h})$, and $85 \%$ vehicles decelerated by $11 \mathrm{mile} / \mathrm{h}(18 \mathrm{~km} / \mathrm{h})$ when driving between the speed humps. This study demonstrates that a single chicane or speed hump has a deceleration effect, but the combination design of a speed hump and a chicane can achieve significant deceleration effects.

In 2010, Aoki [54] used a dual-wheel vehicle model to scan the running path of a fire vehicle and measured the geometric size (lane length, lateral deviation, and width) of chicanes. Moreover, a photoelectric sensor was employed to test the passing time and speed of the wheels. The chicanes with different structural forms and sizes were tested repeatedly. The test showed that the lateral migration of chicane has a significant impact on vehicle speed. When the lane width is large enough $(5.5 \mathrm{~m})$, the chicane has great influence on vehicle speed. Moreover, the structural form and the minimum size of the large-scale fire engine passing the chicane were determined.

With the acceleration and environmental impact as the evaluation indexes, Lee [55] analyzed the traffic calming effect of speed humps, deceleration zones, and chicanes using VISSIM microscopic simulation and MOVES model in 2013. Rahman [56] used paired comparison method and regression model to study the influencing factors of traffic calming, finding that street calming demand is significantly related to pedestrian crosswalks.

Solowczuk [57] analyzed test data and found that the location of parking lanes can influence deceleration, which mainly depends on the width of the remaining lanes. However, the current sustainable design guideline does not specify the time interval between lane routes using alternate lane departure to reduce the speed, noise, pollution and exhaust emission.

In addition to residential road design, chicane design theory has also been introduced to other systems, such as raceways and laser beams. For example, Leonard [58] set the damage condition of cars and motorcycle drivers before and after setting up a chicane; the study showed that the injury rate of drivers decreased significantly after the addition of the chicane, while the injury rate of motorcycle drivers did not have any evident changes, indicating that the chicane helps to improve the safety of cars on the raceway.

In 2016, on the basis of the characteristics of chicane structure and energy transmission theory, experts from California used chicane design theory to optimize the design of laser beam propagation line compensation for sharp turns when developing the linear accelerator light source-II (LCLS-II). Qiang [59] studied the optimization design of compensation sharp turns before the space charge effect.

The study of traffic calming technology in China is still in its infancy and mainly refers to internal experiments and the application of relevant measures in urban residential areas, campuses, and rural roads, which are mostly used to prevent traffic accidents. In the 1980 s, chicanes gradually appeared in some campuses and residential areas, which were set to reduce the safety of pedestrians and nonmotorized vehicles. No study of chicane design is available in China, and only its applicability in urban residential areas has been systematically evaluated.

In 2008, Wan Sen [60] studied the optimization of road traffic in residential areas and proposed to adopt trafficcalming tortuous traffic lanes (chicanes) on the main roads. Chicanes can avoid noise and exhaust emission caused by speed humps while decreasing vehicle speed.

Subsequently, Tang [61] determined the functions of different roads, and proposed the advantages, disadvantages, and applicable conditions of chicanes in urban residential areas according to the implementation principle of traffic calming.

In 2012, Han [62] took electric bicycles as the experimental object and carried out experiments on traffic calming facilities, such as chicanes, speed humps, and road narrowing. The results demonstrated that chicanes have evident effects on vehicle speed reduction, which is second only to speed humps. In the same year, Xu Lei et al. discussed the necessity and feasibility of traffic calming, including chicanes in rural road systems [63].

In 2015, Jiangsu Province issued the Guideline to Traffic Design for Urban Roads in Jiangsu, which clarified the design plan of traffic calming engineering facilities and 
Chunli Zhang, Song Qin, Hongjiang Yu, Binshuang Zheng and Zhen Li/

Journal of Engineering Science and Technology Review 13 (4) (2020) 188 - 197

provided design guidelines for various traffic calming measures, such as chicanes [64].

In 2019, Zhu [65] analyzed the change characteristics of vehicle speed in bend sections and further studied the requirements for speed.

At present, no installation standard has been implemented for deceleration measures, such as traffic calming, in China, and only a relevant standard of rumble strips has been formulated [66]. Developed countries, especially the United States, have already promulgated the guidance standard document for the implementation of traffic calming, such as the "Highway and Street Geometry Design Policy" [67] issued by AASHTO, the "Unified Traffic Control Equipment Handbook" [68] issued by FHWA, the "Guideline for Urban Street Design" issued by the National Transportation Association [69] and the "Guideline for Design and Application of Speed Hump" issued by ITE. In future traffic calming development, the guidelines for the design of traffic calming measures must be perfected.

With good appearance, environmental protection, and deceleration effect, chicanes have been widely applied in North America and developed cities in Europe. However, several differences are observed in various countries in terms of traffic conditions, traffic rules, topography, climate characteristics, and traffic impact, which make the design codes and standards of chicanes unified. Chicanes have not been promoted in China and other countries in Asia. With the deepening of a "people-oriented" transportation planning concept, traffic calming measures have increasingly important positions in traffic environment where people and vehicles coexist harmoniously, such as campuses, parks, and urban residential areas. In addition, chicanes are superior to other traffic calming measures in deceleration and traffic landscape beautification. Combined with the development status of chicanes, this study expounds the geometric design features and relevant design criteria of chicanes and thoroughly analyzes uncertain factors influencing chicane design. Moreover, the main problems in the current study of chicanes and the direction of future studies are expected from the three aspects of design theory, application field, and pavement performance.

\section{Geometric design of chicanes}

According to the development of traffic calming theory and the characteristics of road services, the structure of chicanes has been gradually diversified, such as one-way and twoway roads (as shown in Figure 2), horizontal roads, slopes, road extensions, and independent structures. The design ideas are consistent with the traffic calming concept, that is, to limit vehicle speed, realize the harmonious coexistence of people and vehicles, ensure the traffic demand of special vehicles (fire, ambulance, and garbage disposal), provide parking space on roads, and offer a good traffic environment for pedestrians and non-motorized vehicles.

The geometric design elements of standard chicanes include free view width $a$, lane width $b$, and stagger length $l$, as shown in Figure 2 (a). Free view width $a$ is the visible spatial distance between structures in chicane. It can be either positive or negative, which is dependent on whether spacing or overlap exists between the adjacent extending curbs. Lane width $b$ is the average width of entrance and exit routes, and $b=\left[b_{1}+b_{2}\right] / 2$. Stagger length $l$ is the distance between the most outer edge points of two adjacent extending curbs in chicane.

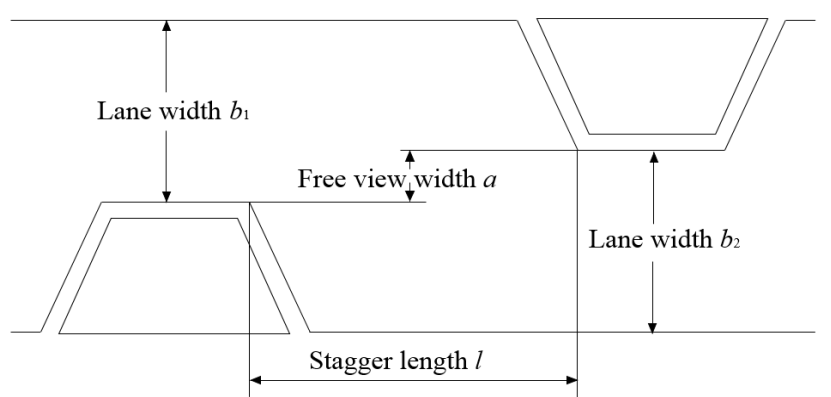

(a) Chicane layout for one-line, one-way street

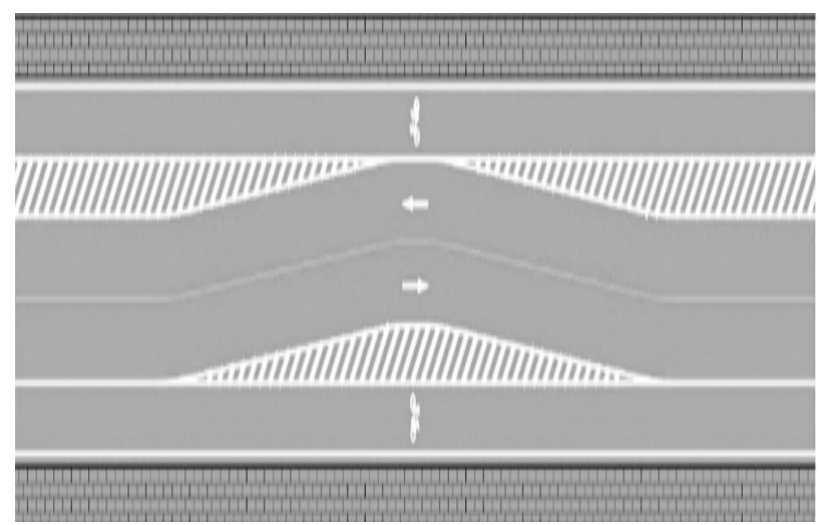

(b) Chicane layout for two-line, two-way street

Fig. 2. The geometric design of chicanes

The results for the literature review show that the speed of vehicles when passing a chicane is related to the path angle [70]. A path angle is formed by changing the lane through the chicane. It is derived from the horizontal deflection distance and the stagger length $l$ formed by the outer edge of the chicane structure, which is the route angle when vehicles pass through the chicane. The specific geometric schematic diagram is shown in Figure 3. An increase in the path angle also entails an increase in the lateral deviation and speed reduction [71].

Path angle $\theta$ :

$\theta=\tan ^{-1} \frac{\left(b_{1}+b_{2}\right) / 2-a}{l}$

Stagger length $l$ :

$l=\frac{\left(b_{1}+b_{2}\right) / 2-a}{\tan \theta}$

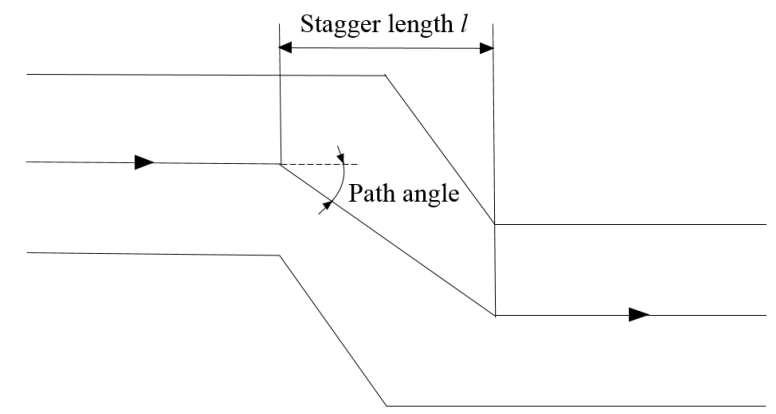

Fig. 3. Definition of path angle 
Chunli Zhang, Song Qin, Hongjiang Yu, Binshuang Zheng and Zhen Li/

Journal of Engineering Science and Technology Review 13 (4) (2020) 188 - 197

\section{International design criteria}

\subsection{Pennsylvania design criterion}

According to the recommended size by the Pennsylvania Traffic Safety Manual [72], a chicane should be designed on a lane that is 12 feet wide, and the stagger length of the chicane should be maintained within the normal range of 5080 feet. According to the Los Angeles Urban Road Design Instruction Manual [73], the starting point of the path should be set at 66 feet from the starting point of the chicane. The "chicane sign" (W1-5l) and appropriate "warning sign" (W13-1) should be set at least 150 feet before the chicane. Moreover, reflectors, street lighting, and elevated landscape should be used to improve the visibility. The design is shown in Figure 4.
As for the relevant design regulations for chicanes, the Pennsylvania Traffic Safety Manual stipulates that traffic volume should be balanced in all directions of the chicane. Otherwise, the chicane loses its deceleration effect. Setting the chicane in an area with large freight traffic flow is inappropriate. According to the road width, parking on the chicane should be prohibited, and the chicane should not be set on the road section with a longitudinal slope greater than $8 \%$. The location of the chicane depends on the actual conditions of the road, such as the location of the lane. Typical devices for chicane construction include control belts, trees, rails, and roadblocks. The safety of the devices must be ensured when setting fixtures or devices along the road.

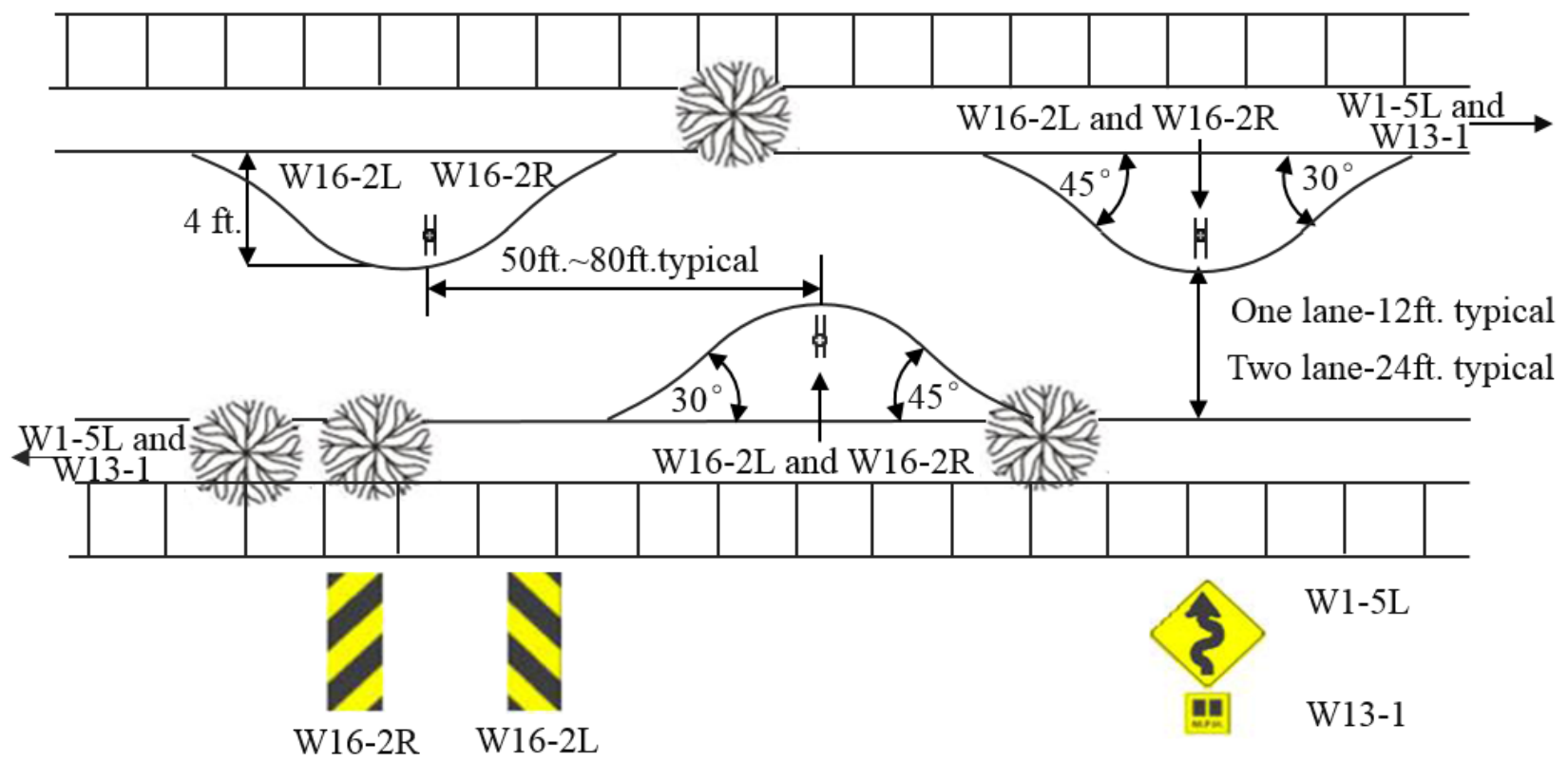

Fig. 4. Recommended chicanes layout in Pennsylvania's traffic calming handbook

\subsection{Delaware traffic calming design manual}

Delaware Traffic Calming Design Manual stipulates that a chicane can be set in two ways: curb and roadside island. Vertical elements should also be set on the roadside island or the curb to attract the attention of drivers. The manual recommends the use of landscape plants, such as slowgrowing shrubs and perennial herbs, as they are easy to maintain as vertical elements. Moreover, setting curbs and roadside islands are recommended to enhance driving safety further. Meanwhile, divisional traffic should be set as a form that can be climbed by motor vehicles at the center of twoline, two-way streets.

The Delaware Traffic Calming Design Manual does not stipulate specific design rules for chicanes but provides a typical design rule, as shown in Figure 5.

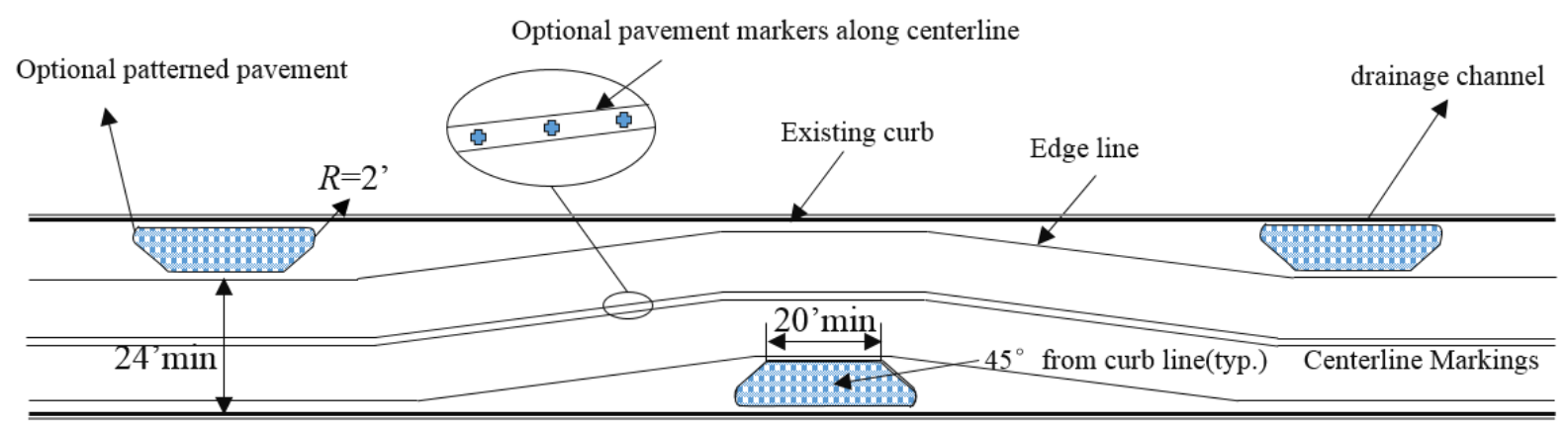

Fig. 5. Recommended layout of chicanes in the Delaware Traffic Calming Design Manual

\section{Uncertain factors influencing chicane design}

The design and layout of chicanes are affected by internal factors, such as road type, deceleration device, traffic flow, lane width, and deflection degree, and external factors, such 
as natural environment, climate change, and human intention. The key of accurate location and design is to make the chicane suitable for the original road traffic demand and conforming to traffic calming theory.

\subsection{Internal factors}

Chicane design is influenced by internal factors, such as road type, deceleration device, traffic flow, and lane width. At present, chicanes are mainly applied to complex and changeable urban roads and streets in residential areas, which have high requirements for speed control. Chicanes can be set in all kinds of urban roads, such as distributed roads and urban arterial roads.

The characteristics of traffic flow play a decisive role in controlling the feasibility of chicanes. Setting chicanes has a high demand for road width and traffic flow. Chicanes, which have a large impact on the driving of vehicles, should not be set in narrow traffic lanes with dense traffic flow [74]. At present, the stipulation for the conditions of setting chicanes varies in different countries. Denmark stipulates that one-way chicanes should be set on roads with no more than 3000 vehicles per day. Some countries have made regulations that state that one-way chicanes should be set on roads with 4000-8000 vehicles per day [75]. In 1992, Hassklau et al. [76] studied block roads and indicated that chicanes should be set on roads with a traffic volume of no more than 600 vehicles per hour. The results of existing studies show that chicanes are designed for urban roads with a speed below $60 \mathrm{~km} / \mathrm{h}$ and a daily traffic volume of less than 3500. Meanwhile, setting chicanes on roads with a great deal of large-scale vehicles, such as trucks, is inadvisable. Chicanes realize bend of roads in two forms of curbs and roadside islands. In the case of small traffic volume, small cars mainly compose the traffic flow. Moreover, speed control has high requirements for speed control. For example, wide curbs or roadside islands can be set on block roads within residential areas. Meanwhile, the free view width $a$ and the stagger length $l$ can be small to achieve higher control effect on vehicle speed.

The specific values of geometric elements of chicanes should be determined according to the control requirements for vehicle speed in chicanes. According to the empirical formula for the geometric design of highway and urban road proposed by AASHTO [77], the relationship between vehicle speed and turning radius is as follows:

$$
R=\frac{v^{2}}{127(e+f)}
$$

where $R$ is the radius of the horizontal curve, $V$ is the speed passing the curve, $e$ is the road superelevation, and $f$ is the road friction coefficient.

However, the meaning of $R$ in the design of traffic calming measures is different from that in traditional road design. In traditional road design, $R$ is the minimum radius value to make the vehicle pass safely and comfortably. However, $R$ is the maximum radius value in the design of traffic calming measures to reduce vehicle speed [78]. The control speed $V$ is substituted to the above formula to realize the purpose of speed control. According to the maximum control radius $R$, the free vi8lew width $a$ and the stagger length $l$ are determined. The lane width $b$ is determined mainly according to the road type and road width. The relationship between chicane width and road width is derived from the existing chicane data in the UK.
The types of chicanes, namely, curb chicanes or roadside island chicanes, play a decisive role in designing the dimension of chicanes. Generally, roadside island chicanes are more economical than curb chicanes, but their appearance is poor. Typical roadside islands are usually trapezoidal rather than semicircular, and the bottom angle of the trapezoid is $45^{\circ}$ to achieve the best speed control effect. The shape of curb chicanes is usually set according to the conical formula. Meanwhile, the type of the road where a chicane is set plays an important role in the design of its width. Chicanes are mainly used in one-line, one-way roads and two-line, two-way roads. For two-line, two-way roads, a median island is set in the chicane to prevent the driver from driving on the opposite lane and to maintain straight driving. When more than two lanes are present, the control effect of chicanes for the fast lane is difficult to guarantee. Meanwhile, setting a chicane when the longitudinal gradient of the road is greater than $6-8 \%$ is inadvisable according to the relevant design manual.

This study investigates the data of chicanes in the UK. The results demonstrate that free view width $a$ and stagger length $l$ are not directly related to road width in chicane design, as shown in Figures 6 and 7. However, the chicane width generally increases with the increase of road width, showing a linear increasing trend, as described in Figures 8 and 9. The relationship between chicane width and road width is expressed by regression equations (4) and (5):

$$
\begin{aligned}
& b_{1}=0.6071 B-0.1511 \\
& b_{2}=0.6930 B-0.6065
\end{aligned}
$$

where $B$ is the road width, and $b_{1}$ and $b_{2}$ are the width at both ends of the chicane.

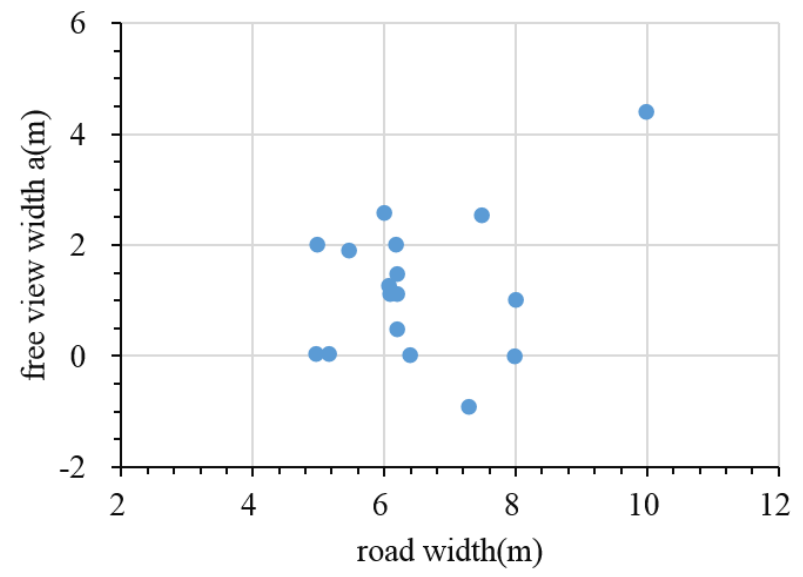

Fig. 6. Relationship between free view width and road width

\subsection{External factors}

(1) Natural environment

At present, international design manuals seldom consider the influence of natural environment on chicane design. Given that chicanes are mainly used in low-speed block roads, they are less affected by the natural environment. Climate change is one of the most influential factors on road performance in the natural environment, which are illustrated in the following paragraph. In addition to climate change, the influence of the natural environment on chicane design is mainly concentrated on the safety and aesthetic layout of vertical space elements of deceleration facilities in chicanes. A reasonable vertical striking element should be 
Chunli Zhang, Song Qin, Hongjiang Yu, Binshuang Zheng and Zhen Li/

Journal of Engineering Science and Technology Review 13 (4) (2020) 188 - 197

set in roadside island chicanes to prompt the drivers to slow down. To ensure the visual range space, suitable shrubs and perennial herbs should be planted on the roadside islands according to the vegetation greening characteristics and ecological environment. Meanwhile, if the local lighting condition is poor, reasonable lighting and reflective signs should be set on roadside islands or curbs.

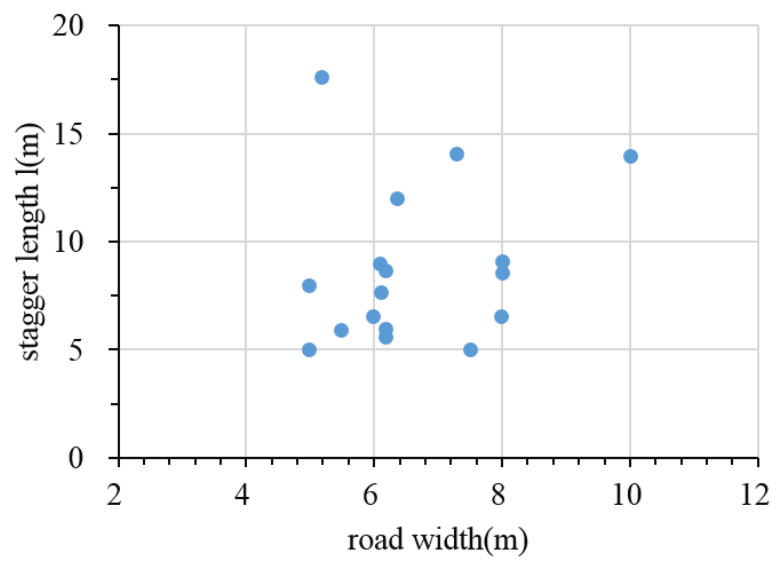

Fig. 7. Relationship between stagger length and road width

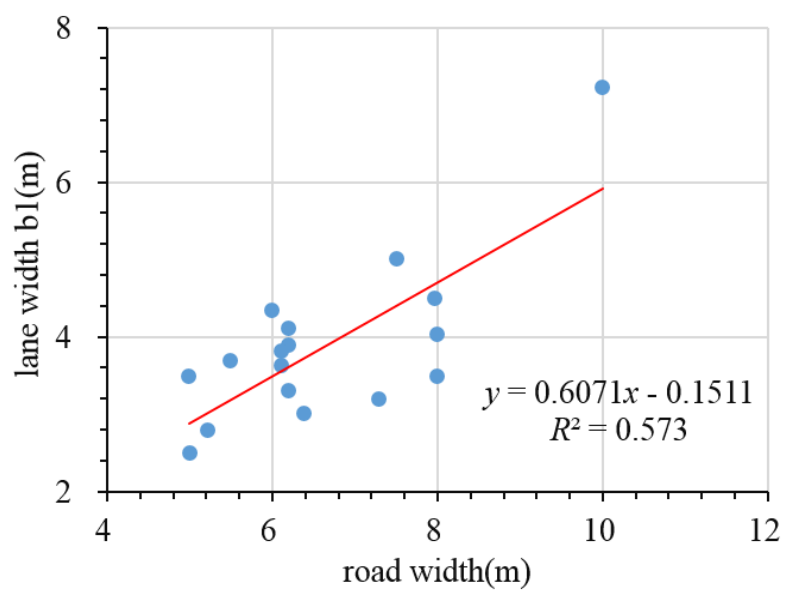

Fig. 8. Relationship between lane width $b_{1}$ and road width

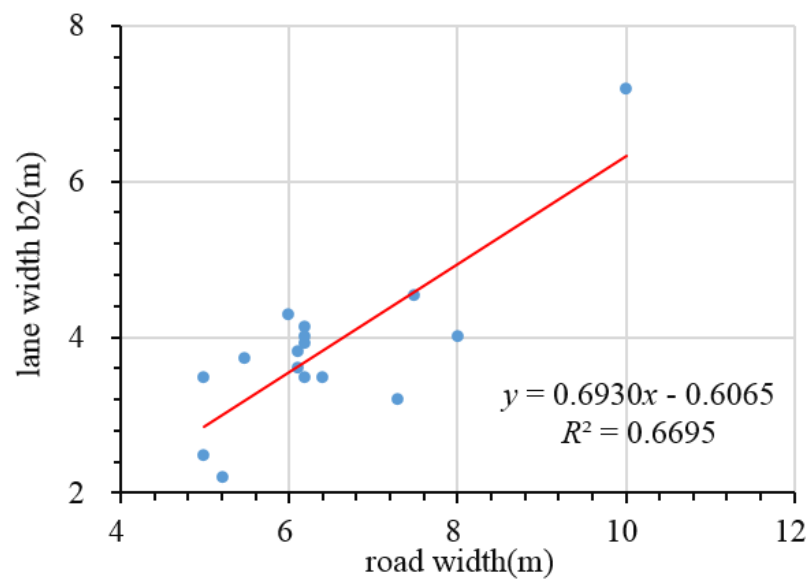

Fig. 9. Relationship between lane width $b_{2}$ and road width

(2) Climate change

Local climate changes have a significant impact on chicane design. Suitable plants should be planted on curbs or roadside islands according to local climate types. If the local climate is wet and rainy, factors, such as skid resistance and drainage, must be considered. Moreover, the geometric size of chicanes, such as free view distance $a$ and stagger length $l$, should be appropriately enlarged to ensure the safety of vehicles running on wet or even water film roads. When chicanes on established roads are added, new superelevation should be reasonably set according to the radius of chicanes to guarantee drainage performance and driving safety.

(3) Human intention

In chicane design, human intention should be considered from two aspects, that is, the intention of drivers and nonmotor vehicle users. When motor vehicle drivers have good driving habits, chicane design mainly depends on nonmandatory guidance facilities for traffic control. Additional mandatory guidance facilities should be considered if drivers have bad driving habits, such as adding a central median island in two-line, two-way lanes, as shown in Figure 10.

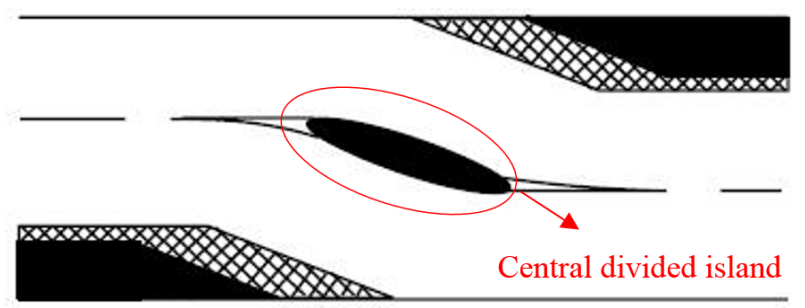

Fig. 10. Median island in two-way road

The intention of drivers should also include the comfort factors of drivers and passengers. In 2014, Bodini established a test system for the comfort of vehicle members in public transport and used a comfort index NVD (VD indicates the passengers in standing position) to evaluate the comfort of vehicle members [79]. The evaluation system can also be applied to evaluate the comfort of traffic calming facilities, including chicanes. Generally, an increase in the stagger distance $l$ and the free view width $a$ entails a rise in the comfort degree.

For the human intention of non-motor vehicle users, the traffic volume of non-motorized vehicles should also be considered. In the case of large traffic volume of nonmotorized vehicles, a strict chicane layout with small free view distance and stagger distance should be adopted. In 1997, Davies et al. [80] proposed to integrate bicycle lanes and chicane facilities in chicane design. For large pedestrian volume, wide roads and long passing time of pedestrians, roadside islands, and median islands should be set as nonmotor vehicle protection areas, which cannot be used by motor vehicles. If the human intention of motor vehicle users is loose, roadside islands and median islands should be set as non-pedestrian protection areas that can be used by motor vehicles to ensure the safety.

\section{Conclusions and prospects}

\subsection{Conclusions}

As an important means of traffic calming technology, chicanes have been developed in North America and the United Kingdom. According to practical international experience, the following conclusions can be drawn:

(1) Chicanes can significantly reduce the vehicle speed and traffic accident rate. At present, two kinds of mature chicanes exist, namely roadside island chicanes and curb chicanes, which are generally used with speed control facilities, such as median islands, speed humps, and deceleration zones. To improve the vehicle speed and traffic flow control effect, chicanes can effectively ensure the 
traffic safety of community roads and non-motorized road users.

(2) Speed control geometric parameters influencing chicanes include free view width a, stagger length 1 , and lane width $b$. Lane width $b$ is mainly affected by road grade and road width, while free view width a and stagger length $l$ directly influence the reduction of vehicle speed. A small free view width $a$ and stagger length $l$ increases the reduction of vehicle speed. Therefore, in the geometric design of chicanes, free view width $a$ and stagger length $l$ should be particularly considered in chicane design.

(3) According to the current internal use experience, chicanes still have certain shortcomings that must be addressed. First, a set of complete design standards for chicane design, which relies mostly on the experience of designers and lacks uniformity and standardization, is needed. Second, chicanes occupy a larger space than other traffic calming measures, such as speed humps. Meanwhile, methods to ensure that motor vehicles running in chicanes consciously abide by traffic rules and avoid irregular driving behaviors should also be formulated.

\subsection{Prospects}

$3 \mathrm{E}$ technology is needed to realize the smooth implementation and achieve the intended purpose of traffic calming, namely engineering measures, education measures, and enforcement measures. However, traffic calming is highly dependent on engineering technology measures. Traffic calming measures are inclined to achieve traffic calming through the self-discipline and non-mandatory law enforcement of traffic travelers. On the basis of the above study and analysis, the study progress of chicane design includes the following aspects:

\section{(1) Design defects}

No uniform design standard has been set for comprehensive evaluation and design according to the actual traffic condition, surrounding environment, and natural climate. At present, chicane design is still under principle guidance in international common design manuals. Moreover, no definite provision has been made on the size of chicanes. The existing design size of chicanes is mainly determined according to the experience of designers. Thus, this study suggests the regulation of key factors in the geometric design of chicanes according to the Pennsylvania Design Criterion and Delaware Traffic Calming Design Manual and an appropriate modification combined with the road conditions and traffic environment in China.

\section{(2) Application field}

At present, chicanes have been used in some countries, and the corresponding problems have also been studied. Chicanes have evident speed and traffic flow control effects in practice. The incidence of traffic accidents also decreases with the reduction of vehicle speed. However, some problems in the practical application of chicanes have been observed. First, in two-way, two-lane chicanes, motor vehicles may cross the lane to decrease the turning range. Second, chicanes also occupy the parking space at roadsides, resulting in a decrease in space use rate. Third, chicanes have an important influence on preventing environmental noise. Some studies use noise level as an indirect replacement index for safety factors [81]. In 2013, Lee [82] simulated two chicanes and multiple chicanes through a computer simulation and obtained the comparison results of vehicle noise and exhaust emission under chicanes and speed humps. However, the simulations only compared chicanes with other types of traffic calming measures but did not explore the influence of geometric size of chicanes on noise and exhaust emission.

Although chicanes decrease the average speed of vehicles and reduce the noise, the carbon emission and noise caused by frequent braking, acceleration, and steering of vehicles passing chicanes have not been strictly examined and evaluated. Zero carbon emission is the key objective of future smart city construction in the field of traffic planning [83]. Carbon emission should be considered in chicane design to determine the optimal design plan. Meanwhile, the economic rationality of noise and emission requires further studies.

\section{(3) Road performance}

Given the low vehicle speed and frequent acceleration, deceleration, and steering behaviors at chicanes, vehicle load has evident pushing and shearing effects on road structure. Therefore, the requirements for the road performance of chicanes are mainly reflected in high-temperature performance, such as rut resistance and pushing resistance, and the anti-slide performance on rainy and snowy days [84]. The study of road performance of chicanes is scarce, and the disease types and actual reference cases are few. Relevant studies should be further carried out.

Given that the high-temperature performance of urban roads is related to vehicle speed, coupling exists between the vehicle speed and geometric parameters of chicanes. The high-temperature performance of chicanes with different geometric sizes also varies, and the coupling relationship should be further determined. Moreover, given that the main service object of chicanes is to decrease the speed of traffic flow, the concrete mixture design of chicanes should be based on shear resistance. The design criteria of concrete mixture must also be determined.

Based on the successful experience in the field of traffic calming technology in developed cities and the current situation of road traffic in China, integrating traffic with the living quality, travel safety, humanization, and environmental landscape is the future study direction for traffic personnel in China.

\section{Acknowledgements}

This work was supported by the Construction Science and Technology Plan Project of Chongqing (Construction and Scientific 2018 Project No. 1-5-3)

This is an Open Access article distributed under the terms of the Creative Commons Attribution License

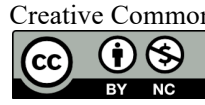




\section{References}

1. Zalewski A, Kempa J, "Traffic calming as a comprehensive solution improving traffic road safety". In: IOP Conference Series: Materials Science and Engineering, New York, USA: IOP Publishing, 2019, pp. 062035.

2. Rahman F, Joewono T B, Al Masum S, "Application of traffic calming devices in developing countries: learning lesson from Bangladesh”. Journal of transportation technologies, 8(02), 2018, pp.119-135.

3. Sahu R, Elumalai S P, "Identifying speed hump, a traffic calming device, as a hotspot for environmental contamination in trafficaffected urban roads". ACS omega, 2(9), 2017, pp.5434-5444.

4. Jazcilevich A, Vázquez J M M, Ramírez P L, et al, "Economicenvironmental analysis of traffic-calming devices". Transportation research part D: transport and environment, 36, 2015, pp.86-95.

5. Lu Y J, Wang L J, Yang Q, et al, "Analysis of asphalt pavement mechanical behaviour by using a tire-pavement coupling model". International Journal of Simulation Modelling, 17(2), 2018, pp.245-256.

6. $\mathrm{Xu} \mathrm{L} \mathrm{J,} \mathrm{Yan} \mathrm{H} \mathrm{W}$, Liu X H, "Design of parameter combination of visual illusion deceleration markings in ice and snow curve". Journal of Highway and transportation Research and Development, 36(03), 2019, pp.124-129.

7. Ewing R H, "Traffic calming: state of the practice". Regulatory Constraints, Slide Seminar, 12, 1999, pp.1-35

8. Buchanan C, "Traffic in towns a study of the long term problems of traffic in urban areas". London: Her Majesty's Stationery Office Press, UK, 1963, pp.22-24.

9. Macpherson G, "Highway and transportation engineering and planning". Tokyo: Longman Scientific \& Technical Press, Japan, 1993, pp.2-9.

10. Taylor D, Tight M, "Public attitudes and consultation in traffic calming schemes". Transport Policy, 4(3), 1997, pp.171-182.

11. Chen G, "Application of traffic calming in urban residential areas". Science \&Technology Association Forum, 8, 2011, pp.189-190.

12. Elvik R, "Area-wide urban traffic calming schemes: a meta-analysis of safety effects”. Accident Analysis \& Prevention, 33(3), 2001, pp.327-336.

13. Jin J., "Discussion about urban traffic calming". Journal of Transportation Engineering and Information, 2, 2003, pp.82-86.

14. Donahue K E, "Urban access and permeability: a study of traffic calming". Master thesis of University of Texas at Austin, Austin, 1995, pp.12-14.

15. Boulter P G, Latham S, Ainge M, "Driving cycles for measuring passenger car emissions on roads with traffic calming measures". The Science of the Total Environment, 235, 1999, pp.77-89.

16. Brindle R E, "Living with traffic twenty-seven contributions to the art and practice of traffic calming". Transportation Research Part Policy and Practice, 30(6), 1996, pp.478-479.

17. Zein S R, Geddes E, Hemsing S, et al, "Safety benefits of traffic calming". Journal of the Transportation Research Board of the National Academies, (1578), 1997, pp.3-10.

18. Shailen Bhatt, Natalie Barnhart, Mark Luszcz, et al, "Delaware traffic calming design manual". In: Meeting of the Transportation Research Board, Delaware, USA: The Traffic Calming Design Manual Committee, 2012, pp.86-89.

19. Garcia A, Torres A J, Romero M A, et al, "Traffic micro-simulation study to evaluate the effect of type and spacing of traffic calming devices on capacity". In: The 6th International Symposium on Highway Capacity and Quality of Service Stockholm, Stockholm, Sweden: Elsevier, 2011, pp.270-281.

20. Cottrell W D, Kim N, Martin P T, et al, "Effectiveness of traffic management in Salt Lake city, Utah". Journal of Safety Research, 37, 2006, pp.27-41.

21. Dennis D, Alexandria D S, Osama F, "Traffic calming manual" Sarasota: City of Sarasota Engineering Department Press, USA, 2003, pp. 20-25.

22. Carmen H K, "Civilized streets a guide to traffic calming". Brighton: Transport Planning 10 Clermont Terrace, UK, 1992, pp.1-9.

23. Halmark, S L, Hawkins N R, Fitzsimmons E, et al, "Use of physical devices for traffic calming along major roads through small rural communities in Iowa". Journal of the Transportation Research Board, 2078, 2008, pp.100-107.
24. Lamberti R, Abate D, De Guglielmo M L, et al, "Perceptual measures and physical devices for traffic calming along a rural highway crossing a small urban community: speed behavior evaluation in a driving simulator". In: Proceedings of the 88th Transportation Research Board Annual meeting, Washington, D. C., USA: TRB, 2009, pp. 12-25.

25. Zech W C, Walker D, Turochy R E, et al, "Effectiveness of speed tables as a traffic calming measure on a college campus street". In: Proceedings of the 88th Transportation Research Board Annual meeting, Washington, D. C., USA: TRB, 2009, pp. 40-45.

27. Finch D J, Kompfner P, Lockwood C R, et al, "Speed, speed limits and accidents". In: Proceedings of the 58th Transport Research Laboratory Project Report, Berkshire, UK: Transport Research Laboratory, 1994, pp. 4-7.

28. Ramirez J A R, Trentesaux D, "Multidisciplinary engineering to solve the problem of congestion in vehicular systems". DYNA, 93(5), 2018, pp.471-471.

29. Webster D C, Mackie A M, "Review of traffic calming schemes in $20 \mathrm{mph}$ zones". In: Proceedings of the 60th Transport Research Laboratory Project Report, Berkshire, UK: Transport Research Laboratory, 1996, pp. 1-10.

30. Zein S R, Geddes E, Hemsing S, et al, "Safety benefits of traffic calming". Journal of the Transportation Research Board of the National Academies, 1578, 1997, pp.3-10.

31. Sarkar S A, Nederveen A J, Pols A, "Renewed commitment to traffic calming for pedestrian safety". Journal of the Transportation Research Board of the National Academies, 1578, 1997, pp.11-19.

32. Ahn K, Rakha H, Trani A, et al, "Estimating vehicle fuel consumption and emissions based on instantaneous speed and acceleration levels". Journal of Transportation Engineering, 128, 2002, pp.182-190.

33. Jiang Y B, Jiang L H, Qin Y Q, et al, “ “Effects of Traffic Calming Measures on Vehicle Speed Control and Road Safety”. Applied Mechanics and Materials, 2014, 2014, pp. 39-42.

34. Tu S W, Zhao Z H, Yao C W, et al, " "Calming" deceleration technology and its experimental research for urban exit / entrance roads". Highway, 63(11), 2018, pp.194-199.

35. Abbott P G, Phillips S M, Layfield R E, "Vehicle and traffic noise surveys alongside speed control cushions in York". In: Proceedings of the 59th Transport Research Laboratory Project Report, Berkshire, UK: Transport Research Laboratory, 1995, pp. 9-17.

36. Webster D C, "Road humps for controlling vehicle speeds". Journal of the Transportation Research Board of the National Academies, 18, 1993, pp. 49-52.

37. Webster D C, "Speeds at 'thumps' and low height road humps". Journal of the Transportation Research Board of the National Academies, 101, 1994, pp.30-39.

38. Hodge A R, "Speed contorl humps: a trial at Transport Research Laboratory". Journal of the Transportation Research Board of the National Academies, 32, 1993, pp. 21.

39. Layfield R E, Hodge A R, Parry D I, "On-road trials of speed cushions in Sheffield and York". In: Proceedings of the 58th Transport Research Laboratory Project Report, Berkshire, UK: Transport Research Laboratory, 1994, pp. 34-38

40. Abate D, Dell Acqua G, Lamberti R, et al, "Use of traffic calming devices along major roads thru small rural communities in Italy". In: Proceedings of the 73rd the Transportation Research Board Annual Meeting, Washington, D.C, USA: Transportation Research Board, 2009, pp.9-15.

41. Litman T, "Taffic calming benefits, costs and equity impacts". Victoria Transport Policy Institute, (7), 1999, pp 10-16.

42. Jin J, "Traffic calming intention research of urban residential areas". Journal of Transportation Engineering and Information, 4(2), 2006, pp 10-16.

43. Chen K W, "Research on traffic calming measures based on speed limit". Master thesis of Beijing Jiaotong University, China, 2019, pp.20-24.

44. Xu L J, Zhou R N, Luo H S, "GESTALT psychology - based traffic calming design method for open campus". Journal of Wuhan University of Technology (Transportation Science \& Engineering), 43(06), 2019, pp.1022-1026.

45. Wheeler A H, Abbott P G, Godfrey N S, et al, "Traffic calming on major roads: the A47 trunk road at Thorney, Cambridgeshire". In: Proceedings of the 238th Transport Research Laboratory Report, Berkshire, UK: Transport Research Laboratory, 1997, pp. 1-11. 
Chunli Zhang, Song Qin, Hongjiang Yu, Binshuang Zheng and Zhen Li/

\section{Journal of Engineering Science and Technology Review 13 (4) (2020) 188 - 197}

46. Kjemtrup K, "Speed reducing measures". In: Proceedings of the 14th Australian Road Research Board (ARRB) Conference, Canberra, Australia: ARRB, 1988, pp.1-4.

47. Sayer I A, Parry D I, "Speed control using chicanes-a trial at Transport Research Laboratory". In: Proceedings of the 102nd Transport Research Laboratory Report, Berkshire, UK: Transport Research Laboratory, 1994, pp. 1-5.

48. Zheng Z, Ahn S, Monsere C M, "Impact of traffic oscillations on freeway crash occurrences". Accident Analysis and Prevention, 42, 2010, pp. 626-636.

49. County Surveyor's Society, "Traffic calming in practice". London: Landor Publishing Ltd., UK, 1994, pp.24-27.

50. Sayer I A, Parry D I, "Speed control using chicanes-a trial at transport research laboratory". Washington, D.C: Transport Research Laboratory, USA, 1994, pp.1-35.

51. Department for transport, "Traffic advisory leaflets 12/97 chicane schemes". London: UK Department for Transport Press, UK, 1997, pp. 23-58.

52. Kawakami M, Babasaki K, Hori T, et al, "Study on effect of traffic calming by experimental road arrangement using chicanes: case study of Nagamachi district in Kanazawa city". Doboku Gakkai Ronbunshuu D, 14, 1997, pp. 727-735.

53. Marek J, "Midblock speed control: chicanes \& speed humps". Institute of Transportation Engineers Journal, 68, 1998, pp. 16-24.

54. Aoki H, Kubota H, Yamada H, et al, "A study on geometric form and size of chicanes and their speed control effects". Doboku Gakkai Ronbunshuu D, (4), 2010, pp. 253-260.

55. Lee $\mathrm{G}$, Joo $\mathrm{S}, \mathrm{Oh} \mathrm{C}$, et al, "An evaluation framework for traffic calming measures in residential areas". Transportation Research Part D: Transport and Environment, 25, 2013, pp. 68-76.

56. Rahman F, Kubota H, "Point scoring system to rank traffic calming projects". Journal of traffic and transportation engineering (English edition), 3(4), 2016, pp. 324-335.

57. Sołowczuk A, Gardas P, "Effect of the parking lane configuration on vehicle speeds in home zones in Poland". Sustainability, 12(2), 2020, pp. 588-589.

58. Leonard L, Lim A, Chesser T, et al, "Does changing the configuration of a motor racing circuit make it safer". British Journal of Sports Medicine, 39(3), 2005, pp. 159-161.

59. Qiang J, Mitchell C E, Venturini M, "Design optimization of compensation chicanes in the LCLS-II transport lines". In: Proceedings of the 7th International Particle Accelerator Conference, Busan, Korea: Pohang Accelerator Laboratory, 2016, pp.4-8.

60. Wan S, "Study on the residential district road and traffic optimized based on traffic calming". Traffic and Transportation, 5, 2008, pp. 45-48.

61. Tang T P, Ma J X, Liao X Q, “Application of traffic calming in urban residential areas”. Forest Engineering, 26(6), 2010, pp. 7478 .

62. Han S, "Research on the adaptation of traffic calming in slow road lines". Master thesis of Changsha University of Science \& Technology, China, 2012, pp.13-19.

63. Xu L Liu L, "The necessity of traffic calming using in rural roads system”. Journal of Anhui Agricultural Sciences, 40(35), 2012, pp. 17164-17166.

64. Huang J, “Traffic calming design”. Jiangsu Construction, 3, 2016, pp. 163-169.

65. Zhu X J, "Speed requirements of vehicles on the road turning". Automobile Applied Technology, (07), 2019, pp. 214-215+224.

66. Ministry of Public Security of the People's Republic of China, "Code for layout of urban road traffic signs and markings: $G B$ 51038-2015". Beijing: China Planning Press, China, 2015, pp.23-32.
67. AASHTO, "Policy on geometric design of highways and streets fifth edition". Washington, D.C: American Association of State Highway and Transportation Officials, USA, 2005, pp.44-56.

68. Federal Highway Administration, "Manual on uniform traffic control devices for streets and highways". Washington, D.C: Federal Highway Administration, USA, 2009, pp.23-29.

69. AASHTO, "Policy on geometric design of highways and streets fifth edition". Washington D C: American Association of State Highway and Transportation Officials, USA, 2005, pp.44-56.

70. Chan S, Vehabovic E, Velez A, "The relationship between geometry and vehicle speed of chicanes". In: Proceedings of the 96th the Transportation Research Board Annual Meeting, Washington, D.C, USA: the Transportation Research Board, 2017, pp.1-11.

71. Sayer I A, Parry D I, Barker J K, "Traffic calming-an assessment of selected on-road chicane schemes". Berkshire: Transport Research Laboratory, UK, 1998, pp.6-11.

72. Pennsylvania Department of Transportation, "Pennsylvania's traffic calming handbook". Pennsylvania: Pennsylvania Department of Transportation Press, USA, 2012, pp.13-19.

73. Los Angeles County Department of Public Works, "LA county neighborhood traffic management program-toolbox-chicanes specifications". Los Angeles: Los Angeles County Department of Public Works, USA, 1998, pp.34-37.

74. Yin J. Glance on traffic calming of lyons, "Glance on traffic calming of lyons". Public Communication of Science \& Technology, 3, 2011, pp. 30

75. Belz N P, Aultman-Hall L, "Analyzing the effect of driver age on operating speed acceleration noise". Journal of the Transportation Research Board, 2265, 2011, pp. 184-191.

76. Hassklau C, Nold I, Boecker G, et al, "Civilised streets: a guide to traffic calming”. Brighton: Environmental and Transport Planning, UK, 1992, pp.56-73.

77. American Association of State Highway and Transportation Officials, "A policy on geometric design of highways and street". Washington, D.C: American Association of State Highway and Transportation Officials, USA, 2004, pp.23-29.

78. Dong Y P, "Study on the road traffic calming technology for the medium-small cities". Master thesis of Kunming University of Science and Technology, China, 2008, pp.34-37.

79. Bodini I, Lancini M, Pasinetti S, et al, "Techniques for on-board vibrational passenger comfort monitoring in public transport". ACTA IMEKO, 3(4), 2014, pp. 32-37.

80. Davies D G, Ryley T J, Taylor S B, et al, "Cyclists at road narrowings: 241st TRLR-1997". In: Proceedings of the 24lst Transport Research Laboratory Report, Berkshire, UK: Transport Research Laboratory, 1997, pp. 2-7.

81. Oh D, Oh C, Chang M, "Methodology for evaluating freeway interchange spacing for high design speed based on traffic safety: focused on analysis of acceleration noise using microscopic traffic simulations". Journal of Korean Society of Transportation, 27(5), 2009, pp. 145-153.

82. Lee G, Joo S, Oh C, et al, "A comprehensive evaluation framework of traffic calming measures in residential area". In: Proceedings of the 92nd the Transportation Research Board Annual Meeting, Washington, D.C, USA: the Transportation Research Board, 2013, pp.68-76.

83. Urrutia-Azcona K, Stendorf-Sørensen S, Molina-Costa P, et al, "Smart zero carbon city: key factors towards smart urban decarbonisation". DYNA, 94(6), 2019, pp. 676-683.

84. Stanislawek S, Dziewulski P, Kedzierski P, "Deterioration of road barrier protection ability due to variable road friction". International Journal of Simulation Modelling, 18(3), 2019, pp. 432-440. 